\title{
Digital analogue of an agricultural tractor
}

\author{
Otari Didmanidze ${ }^{1}$, Nikolay Pulyaev ${ }^{1 *}$, Sergey Devyanin ${ }^{1}$, and Dzhabir Asadov ${ }^{1}$ \\ ${ }^{1}$ Russian State Agrarian University - Moscow Timiryazev Agricultural Academy, 49 \\ Timiryazevskaya str., Moscow, 127550, Russian Federation
}

\begin{abstract}
Today the trend in the digitalisation of all economic spheres is particularly noticeable. Agriculture is no exception here. According to forecasts, the agribusiness transition to Industry-4.0 will increase the yield by $10 \%$. One of the digital design and modeling technologies is the use of digital analogues of objects or processes. This technology can be applied to an agricultural tractor or other power device. Using this approach will allow you to plan the annual load of machines, taking into account their maintenance condition, efficiency of use, etc. Also such a system will allow to choose the optimal operating modes of agricultural machinery, which in turn will increase its capacity, yield and reduce losses.
\end{abstract}

At the International Economic Forum held in Geneva in November 2017, 10 key technologies of the 4th industrial revolution were identified. One of them was digital design and modeling. According to the materials of the "Techuspech" rating, this technology is a key factor of competitiveness.

Digital design and modeling is a set of technologies for mathematical modeling, computer design, computer and supercomputer engineering, pre-production technologies, "digital analogues", product data management and product lifecycle management $[1,2]$.

So the "digital analogue" is a long-term direction for the development of production processes and modern power devices. Their use allows to reduce the cost of development, operation and maintenance of equipment.

According to the experts of the National Technological Initiative "New Production Technologies" Center the digital analogue is a single model that reliably describes all the characteristics, processes and relationships, both for an individual object and for the entire production. That is, a virtual copy of the physical world is created, where all data about materials, design features, operations performed, etc. are recorded, which is able to reproduce its state under various conditions. At its core, a digital analogue is a set of mathematical formulas that describe an object and the processes occurring in it [3].

Today such technologies are used mainly in the design of new products as well as in the optimization of technological processes. Digital analogues are firmly established in different industries and solve very specific tasks. This allows to reduce the design time and create world competitive and in-demand products of new generation. Digital design and simulation capabilities reduce the number of field tests by a factor of 20 by increasing the number of virtual tests. This is especially noticeable in the automobile industry as a highly competitive sector of the economy [4-6].

\footnotetext{
*Corresponding author: inpo.msau@gmail.com
} 
The digital analogue appears at the stage of technical design of the object, with its help the product is modified and refined. However after the object is made such a model requires constant updating in order to match its current state. This can be done with the help of numerous IoT sensors installed on the ready-made product which allows to obtain and analyze data during the entire life cycle of a real product [7-9].

The digital analogue also allows to perform a predictive analysis of the resource, thus reducing the repair cost providing the opportunity to carry out the necessary maintenance in advance, without bringing the equipment to overhaul.

A similar system might look like this. The two operating machines are equipped with sensors that take system readings and transmit them to the digital analogues of both machines. In computer engineering programs at virtual test sites, simulations are carried out directly taking into account the actual loads that the sensors detect. This allows to detect the beginning of defects and deformations before they become noticeable to the mechanic or repair operator. Accordingly, maintenance or repairs will be carried out in advance, reducing the cost of operating the equipment and increasing its capacity [10].

The Internet of Things - a variety of sensors that obtain data about the operation of the equipment as well as machine learning technologies that help to predict how the system will behave in certain circumstances $[11,12]$.

Modern agricultural machinery has a large number of sensors in its design, which makes it possible to obtain a large amount of information about the operation of systems. And having a large amount of data for a certain period of time, it is easier to identify patterns in the operation of the machine, determine wear degree and the probability of failure of components and assemblies and therefore to reduce the cost of diagnostics and repairs.

But the obtained data must be transferred to the operating center or to a PC for analysis, processing and making further decisions. One of the most important trends in modern agriculture is the use of telemetry devices that are responsible for receiving and transmitting data based on cellular communication technologies. Such devices are mainly used in precision farming systems. For example, John Deere produces StarFire 6000 series receivers operating with both GPS and GLONASS satellites which provide an accuracy of up to $3 \mathrm{~cm}$ [13]. To ensure this accuracy, the receivers interact with satellites in geostationary orbit and other alternative sources-differential correction systems, in order to obtain additional data.

Today the cost of such devices is quite high, but the economic effect can be felt in the next one or two years of their use.

JohnDeere has developed a remote diagnostic complex ExpertAlerts, the so-called "Expert Warnings". The system analyzes inputs from the sensors installed on the agricultural machine and based on the historical array of data on repeated failures and other indicators of problems for this brand of machines, makes an assumption about the state of certain components and units $[14,15]$. This allows to prevent serious breakdowns in advance and avoid repairing or replacing expensive parts. A modern agricultural machine can generate up to 2000 of different technical parameters of the main systems and mechanisms.

A tractor like any power unit can be represented schematically (Fig. 1). The figure shows that all the main systems of an agricultural machine or tractor directly interact with the telematics device in both directions, i.e. they transmit and receive data. 


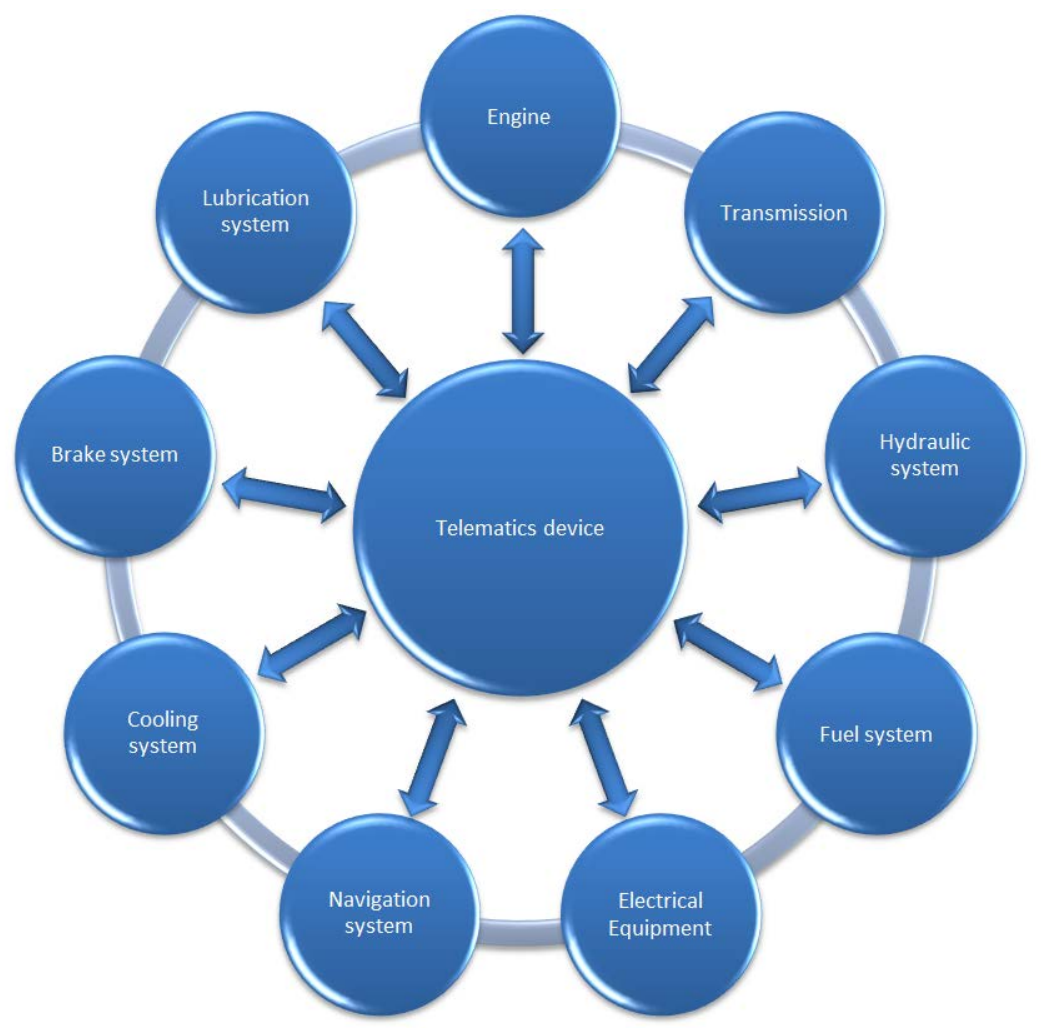

Fig. 1. Diagram of tractor systems interaction with a telematics device.

It can also be said that the systems can interact with each other via a telematics device as well as directly.

Using this approach will allow (for a single machine in real time) to:

1. Control the quality of the machine in combination with the aggregated devices;

2. Evaluate the degree of perfection (optimization) of the processes occurring in the machine;

3. Optimize the operating modes of the machine, taking into account weather conditions and agrotechnological requirements

4. Evaluate the maintenance condition of the machine;

5. Predict changes in the maintenance condition;

6. Determine the source of the violation of the normal operation of the machine;

7. Identify design drawbacks for the machine to solve the tasks set;

8. Detect new effects in operation for machine design modernisation;

9. Allows to control the operating modes of the machine remotely

The possibilities of this approach for a complex of operating machines:

1. Coordination of the machine operation to solve a common problem;

2. Interaction between machines when performing the same task together;

3. Comparison of the performance of identical machines with each other and the overall level.

As part of "digital" economy management the application of this approach will allow to plan the annual load of machines, taking into account their maintenance condition, efficiency of use, etc. Such system will allow to choose the optimal operating modes of agricultural machinery which in turn will increase capacity, yield and reduce losses. 


\section{References}

1. Z.Kh. Shogentsukova, A.Kh. Shogentsukov, Digital aspects of management of the agroindustrial complex of Russia, E3S Web of Conferences, 222, 010 (2020).

2. N.I. Lebed, T.N. Nekrasova, O.V. Popova, Review of modern technologies intellectual decision support in the reclamation of agricultural crops, IOP Conf. Series: Earth and Environmental Science, 577, 012023 (2020).

3. Computer engineering, digital design capabilities, Available at: https://topuch.ru/4kompeyuternij-injiniring-vozmojnosti-cifrovogo-proektirovani/index.html.

4. Yu.V. Chutcheva, Yu.S. Korotkih, N.N. Pulyaev, To the issue of tractor's renewal in the Russian Federation. The economy of agriculture in Russia, v. 5, pp. 19-24 (2020).

5. Yu.V. Chutcheva, N.N. Pulyaev, Yu.S. Korotkih, Promising areas for the development of traction vehicles for agriculture, Machinery and Equipment for Rural Area, v. 9(279), pp. 2-5 (2020).

6. Digital mirror. Digital Twin technologies in the oil and gas industry, Available at: https://www.gazprom-neft.ru/press-center/sibneft-online/archive/2018-septemberprojects $/ 1863687 /$.

7. N.F. Kashapov, M.M. Nafikov, A.R. Nigmatzyanov, O.I. Makarova, V.V. Medvedev, V.A. Chernov, M.D. Nigmatullin, Using digital agricultural production based on navigation and information systems, IOP Conf. Series: Materials Science and Engineering, 915, 012023 (2020).

8. K. Sovin, Technological processes of data exchange between electronic control units ecu on the can bus of the tractor, Agricultural machinery: maintenance and repair, v. 5, pp. 60-66 (2019).

9. 9. K. Sovin Methods of sistematizirovany digital values received on data channel canbus. Agricultural machinery: maintenance and repair, v. 4, pp. 28-31 (2019).

10. N.A. Bolshakov, O.N. Didmanidze, E.P. Parlyuk, Modernization of the cooling system in tractors with gas engines, E3S Web of Conferences, v. 224, 04048 (2020).

11. A. Agumbayeva, E. Chmyshenko, N. Pulyaev, D. Bunkovsky, K. Kolesov, E. Amirova, Industrial transformation of Kazakhstan in digitalization's era, Journal of Advanced Research in Law and Economics, t. 10, v. 6(44), pp. 1861-1867 (2019).

12. V.I Trukhachev, O.N. Didmanidze, S.N. Devyanin, N.N. Pulyaev, Evaluation of the technical condition of the machine according to its control system data, Readings of Academician V. N. Boltinsky, pp. 10-19 (2021).

13. Receiver and StarFire signals. Precision farming technologies, Available at: https://www.deere.ru/ru/\%D1\%81\%D0\%B8\%D1\%81\%D1\%82\%D0\%B5\%D0\%BC\%

D1\%8B-\%D1\%82\%D0\%BE\%D1\%87\%D0\%BD\%D0\%BE\%D0\%B3\%D0\%BE-

$\% \mathrm{D} 0 \% \mathrm{~B} 7 \% \mathrm{D} 0 \% \mathrm{~B} 5 \% \mathrm{D} 0 \% \mathrm{BC} \% \mathrm{D} 0 \% \mathrm{BB} \% \mathrm{D} 0 \% \mathrm{~B} 5 \% \mathrm{D} 0 \% \mathrm{~B} 4 \% \mathrm{D} 0 \% \mathrm{~B} 5 \% \mathrm{D} 0 \% \mathrm{BB} \% \mathrm{D} 0$ $\% \mathrm{~B} 8 \% \mathrm{D} 1 \% 8 \mathrm{~F}-$

ams $/ \%$ D0\%BF\%D1\%80\%D0\%B8\%D0\%B5\%D0\%BC\%D0\%BD $\%$ D0\%B8\%D0\%BA $\% \mathrm{D} 0 \% \mathrm{~B} 8-\% \mathrm{D} 0 \% \mathrm{~B} 8-$

$\% \mathrm{D} 0 \% \mathrm{~B} 4 \% \mathrm{D} 0 \% \mathrm{~B} 8 \% \mathrm{D} 1 \% 81 \% \mathrm{D} 0 \% \mathrm{BF} \% \mathrm{D} 0 \% \mathrm{BB} \% \mathrm{D} 0 \% \mathrm{~B} 5 \% \mathrm{D} 0 \% \mathrm{~B} 8 / \% \mathrm{D} 0 \% \mathrm{BF} \% \mathrm{D} 1$ $\% 80 \% \mathrm{D} 0 \% \mathrm{~B} 8 \% \mathrm{D} 0 \% \mathrm{~B} 5 \% \mathrm{D} 0 \% \mathrm{BC} \% \mathrm{D} 0 \% \mathrm{BD} \% \mathrm{D} 0 \% \mathrm{~B} 8 \% \mathrm{D} 0 \% \mathrm{BA}-$ starfire-6000.

14. Expert alerts, Available at: https://jupiter9.ru/Servis/expert-alerts-ekspertnyepreduprezhdeniya.

15. R.Yu. Solov'yev, S.V. Cheranev, S.B. Karyakin, A.V. Kolomeychenko, I.V. Gribov, About the center of agricultural engineering, Technical service of machines, v. 4(137), pp. 12-18 (2019). 